\title{
Synthesis of Poly(APP-co-EGDMA) Particles Using Monomers Derived from Cashew Nut Shell Liquid for the Removal of $\operatorname{Cr}($ III) from Aqueous Solutions
}

\author{
Joseph Wilson ${ }^{1}$, Joseph Yoeza Naimani Philip², James Epiphan Gabriel Mdoe ${ }^{2}$ \\ ${ }^{1}$ Department of Chemistry, St. John's University of Tanzania, Dodoma, Tanzania \\ ${ }^{2}$ Chemistry Department, University of Dar es Salaam, Dar es Salaam, Tanzania \\ Email: james_mdoe@yahoo.co.uk
}

Received November 15, 2013; revised December 15, 2013; accepted December 22, 2013

Copyright (C) 2014 Joseph Wilson et al. This is an open access article distributed under the Creative Commons Attribution License, which permits unrestricted use, distribution, and reproduction in any medium, provided the original work is properly cited. In accordance of the Creative Commons Attribution License all Copyrights (C) 2014 are reserved for SCIRP and the owner of the intellectual property Joseph Wilson et al. All Copyright (C) 2014 are guarded by law and by SCIRP as a guardian.

\section{ABSTRACT}

This work was aimed at synthesizing Cashew Nut Shell Liquid (CNSL) based polymer particles for adsorption of $\mathrm{Cr}$ (III) ions from aqueous solutions. Natural CNSL was used as a starting material in synthesizing amino pentadecylphenols (APP). This was achieved through isolating anacardic acid from the CNSL via calcium anacardate procedure, followed by hydrogenation of the alkenyl side chains, and subsequently decarboxylating the product to form 3-pentadecylphenol, which was then nitrated and reduced to a mixture of APP. APP were co-polymerized with ethylene glycol dimethacrylate (EGDMA) to form poly(APP-co-EGDMA) particles. The chemical structures of the synthesized compounds were confirmed by Fourier Transform IR and 1H-NMR. The co-polymer particles were characterized by Scanning Electron Microscopy (SEM) to establish their morphological properties. The prepared co-polymer particles were found to have -NH loading of $46 \mathrm{mmol} / \mathrm{g}$ and a maximum adsorption capacity for $\mathrm{Cr}$ (III) ions of $16 \mathrm{mg}$ per g of dry polymer particles. The spent polymer particles were recoverable and reusable.

\section{KEYWORDS}

\section{Cashew Nut Shell Liquid (CNSL); Amino Pentadecylphenols (APP); Poly(APP-co-EGDMA)}

\section{Introduction}

Environmental pollution by heavy metals is a widespread problem nowadays due to increased anthropogenic activities. In most cases, the pollution load ends into water bodies thus threatening not only aquatic organisms, but also the quality of water for domestic uses. Pollution from heavy metals is one of the most serious environmental problems due to the fact that they bio-accumulate causing adverse effects to living organisms [1]. In view of this, their removal from industrial discharged effluents becomes an absolute necessity.

Chromium is one of the heavy metals known to be toxic to humans and aquatic life. Various industrial effluents from pigments, electroplating, dying, canning, textile, leather tanning, paint and steel industries contain substantial amounts of chromium. In general, these industrial effluents contain both $\mathrm{Cr}(\mathrm{III})$ and $\mathrm{Cr}(\mathrm{VI})$ ions. However, it is well established that $\mathrm{Cr}$ (III) is not as toxic as $\mathrm{Cr}(\mathrm{VI})$. Yet under suitable conditions, Cr(III) can readily be oxidized to $\mathrm{Cr}$ (VI) [2], thus underlying the importance of restricting its accumulation in the environment. Furthermore, excessive buildup of $\mathrm{Cr}$ (III) ions can affect the ecology of the environment as well as inhibiting various enzyme systems in living organisms [3,4]. Long term exposure to $\mathrm{Cr}(\mathrm{III})$ is also known to cause cancer and allergic skin reactions [5].

The importance of minimizing the amount of $\mathrm{Cr}$ (III) ions in industrial effluents and other sources has led to the development of a number of removal methods. The commonly used methods for removing such metal ions from aqueous waste include precipitation, lime coagulation, semi-sedimentation, electro-dialysis, chemical reac- 
tion, biological processes, ion exchange, filtration, reverse osmosis, solvent extraction and adsorption [6].

Adsorption process is the most common and is widely reported in the literature. Thus a number of adsorbents ranging from inorganic to organic polymers have been investigated. Examples of studied organic polymers include polystyrene [7], polyaniline [8,9], polypyrrole [10], polypropylcalix [6] arene [11], polyacrylicester [12], poly (MMA-MAGA) [13], poly(GMA-co-EDGMA)-en [14] and polystyrenedivinylbenzene [15]. However, these polymers are prepared from commercial monomers, which are often time-consuming, expensive and not renewable. In an effort to use renewable monomers, we have attempted the synthesis of co-polymer particles using monomers derived from CNSL, a by-product of the processing of cashew (Anacardium occidentale L.) nuts. The co-polymer particles were investigated as adsorbents for the removal of $\mathrm{Cr}(\mathrm{III})$ ions from aqueous solutions.

\section{Experimental}

\subsection{Chemicals and Materials}

Ethylene glycol dimethacrylate (EGDMA) 98\% and sodium nitrate (Aldrich, UK) were used as received. The stock solution containing $1000 \mathrm{mg} / \mathrm{L}$ Cr(III) was prepared by dissolving a known quantity of chromium nitrate nonahydrate (Lobachemie, Mumbai India) in distilled water. This stock solution was diluted as required to obtain the working solutions containing 0.16 to $20.00 \mathrm{mg} / \mathrm{L}$ Cr(III). All other chemicals were of analytical reagent grade and were used as received. CNSL was extracted from cashew nut shells obtained from Mtwara region in Tanzania. Cashew nut shell pieces (725 g) were soaked in cyclohexane $(500 \mathrm{~mL})$ for 3 days; thereafter the shells were sieved out, and the solution filtered and concentrated under reduced pressure using a rotary evaporator at $40^{\circ} \mathrm{C}$. A brownish CNSL product (228 g, 31\%) was obtained. Thereafter, anacardic acid (1) (Scheme 1) was obtained from the CNSL via calcium anacardate procedure as reported elsewhere [16], with a few operational modifications.

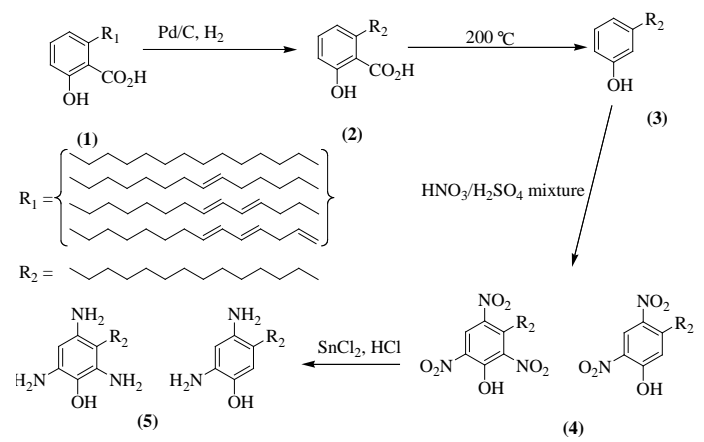

Scheme 1. Different stages in the synthesis of aminopentadecylphenols.

\subsection{Synthesis of Amino-Pentadecylphenols from Anacardic Acid}

The anarcadic acid (50.0 g) was hydrogenated in the presence of palladium catalyst to give 2-hydroxy-6-pentadecyl-benzoic acid (2) (10.60 g, 21.2\%) as off-white crystalline material. IR n $(-\mathrm{COOH})=3500-3100 \mathrm{~cm}^{-1}, \mathrm{n}$ $($ Ar-OH $)=3400-2400 \mathrm{~cm}^{-1}, \mathrm{n}(-\mathrm{COOH})=1631 \mathrm{~cm}^{-1}, \mathrm{n}$ $($ Ar-H $)=3009 \mathrm{~cm}^{-1}$, n (aliphatic C-H $\left.\mathrm{H}_{\mathrm{st}}\right)=2914 \mathrm{~cm}^{-1}$ and $2848 \mathrm{~cm}^{-1}$, n (aromatic C=C) $=1444 \mathrm{~cm}^{-1}$ and $\mathrm{n}(\mathrm{Ar}-\mathrm{OH}$ and $-\mathrm{COOH})=1310 \mathrm{~cm}^{-1}$. The ${ }^{1} \mathrm{H}-\mathrm{NMR}(500 \mathrm{MHz}$, $\mathrm{CDCl}_{3}$ ) showed the substitution pattern of the benzene ring leading to the structure of the product. The presence of three aromatic protons observed at $\delta 6.785$ (d), 6.879 (d), and 7.362 (t) indicates that the product is a tri-substituted benzene. The alkyl protons were observed at $\delta$ 0.862 - $2.983(\mathrm{~m})$. The phenolic and carboxyl protons were assigned at $\delta 5.026$ (m, mixed) and 11.026 (s), respectively. The 2-hydroxy-6-pentadecyl-benzoic acid (2) (9.17 g) was then decarboxylated to 3-pentadecylphenol (3) by heating at $200^{\circ} \mathrm{C}$ for $5 \mathrm{~h}$. The product (7.85 g, 98\%) was obtained as a dark brown liquid that solidified after cooling to room temperature. The IR spectrum shows similar features as for (2), possibly because absorption bands for $-\mathrm{COOH}$ and aromatic -OH groups do overlap. Nonetheless, the ${ }^{1} \mathrm{H}-\mathrm{NMR}\left(500 \mathrm{MHz}, \mathrm{CDCl}_{3}\right.$ ) spectrum displays similar features to that of 2-hydroxy-6-pentadecyl-benzoic except for the absence of exchangeable ArCOOH at $\delta 11 \mathrm{ppm}$ and the presence of a broad peak $(\mathrm{ArOH})$ at around $\delta 4.7-5.0 \mathrm{ppm}$.

The 3-pentadecylphenol (3) (7.85 g) in dichloromethane was nitrated heterogeneously using a mixture of sodium nitrate (10.22 g), sodium hydrogen sulfate monohydrate (16.55 g) in wet silicon dioxide (50\% w/w). Work-up of the reaction afforded yellow precipitates that solidified upon addition of ice water. Re-crystallization of this material from methanol afforded yellow solid (2.70 g). FT-IR spectrum (Figure 1 ) showed the appearance of new distinctive peaks around $1200 \mathrm{~cm}^{-1}$ and $1650 \mathrm{~cm}^{-1}$ that indicate the presence of nitro group.

${ }^{1} \mathrm{H}-\mathrm{NMR}\left(500 \mathrm{MHz}, \mathrm{CDCl}_{3}\right.$ ) (Figure 2) $\delta .0 .9$ - 3.0 ppm are characteristic aliphatic proton peaks; singlet

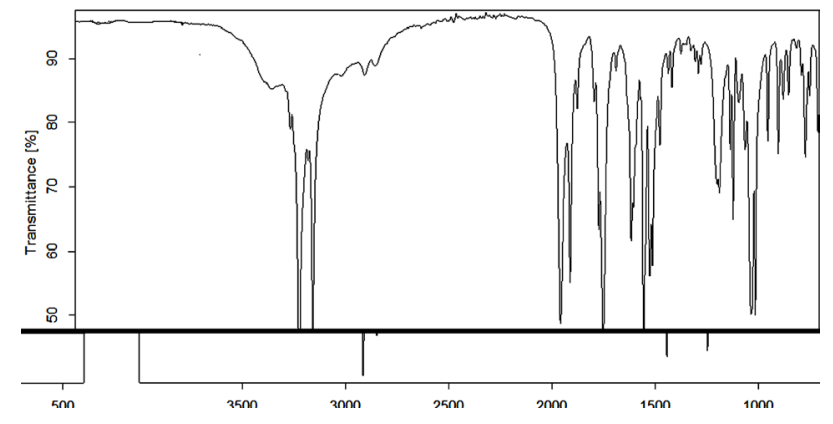

Figure 1. IR spectrum for a mixture of nitro-pentadecylphenols. 
peaks at around $\delta 7.3$ and $9.0 \mathrm{ppm}$ attributed to aromatic protons. Since these peaks are singlets, it implies that the signals are from nonadjacent aromatic hydrogen atoms. It can therefore be predicted that the nitration process resulted to a mixture of di- and tri-nitro compounds, i.e., 5-pentadecyl-2,4-dinitrophenol (with two aromatic protons) and 3-pentadecyl-2,4,6-trinitrophenol (with one aromatic proton). The trinitro product, 3-pentadecyl-2,4,6trinitrophenol, displays a ${ }^{1} \mathrm{H}$ NMR peak at $\delta 9.0 \mathrm{ppm}$ for the aromatic proton between two nitro groups, i.e., more de-shielded. On the other hand, the dinitro product, 5-pentadecyl-2,4-dinitrophenol, displays ${ }^{1} \mathrm{H}$ NMR peaks for the aromatic proton between phenol and aliphatic groups (at $\delta 7.3$, less deshielded), and between two nitro groups (at $9.0 \mathrm{ppm}$, more deshielded). A weak and broad peak at around $\delta 11.2 \mathrm{ppm}$ is associated with phenolic $-\mathrm{OH}$ proton.

Reduction of the mixture of nitropentadecyl phenols (4) (5.0 g) using tin chloride and hydrochloric acid gave compound (5) as black solid. Characterization of this mixture of compounds using IR (Figure 3) showed disappearance of peaks around $1200 \mathrm{~cm}^{-1}$ and $1600 \mathrm{~cm}^{-1}$ $\left(-\mathrm{NO}_{2}\right)$ and appearance of distinctive peaks at 3550 $3110 \mathrm{~cm}^{-1}$ showing axial deformation of $\mathrm{N}-\mathrm{H}$ groups, $1374 \mathrm{~cm}^{-1}$ a strong band corresponding to aromatic amines, at around $1125 \mathrm{~cm}^{-1}$ from axial deformation of the C-N group, $1572 \mathrm{~cm}^{-1}(\mathrm{~N}-\mathrm{H})$ indicating presence of amines.

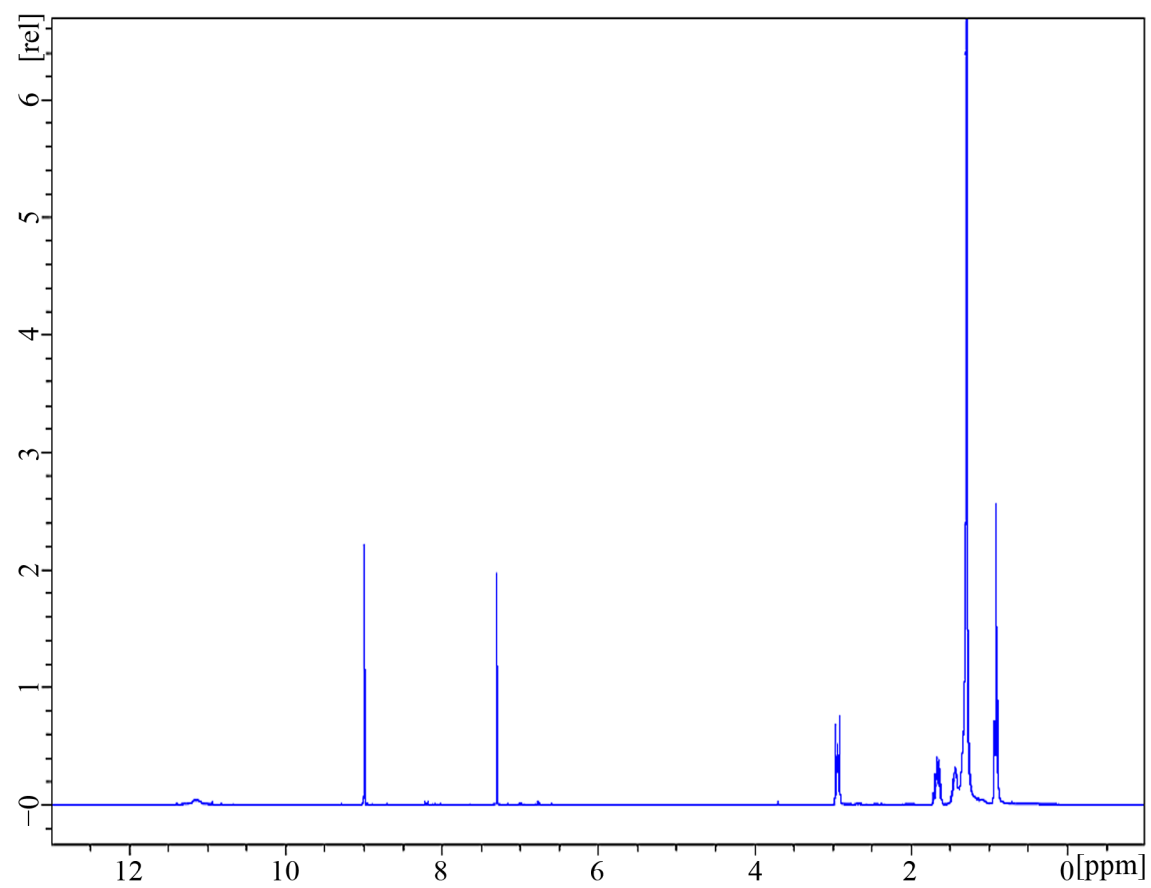

Figure 2. ${ }^{1} \mathrm{H}$-NMR (500 $\mathrm{MHz}, \mathrm{CDCl}_{3}$ ) spectrum for a mixture of nitro-pentadecylphenols.

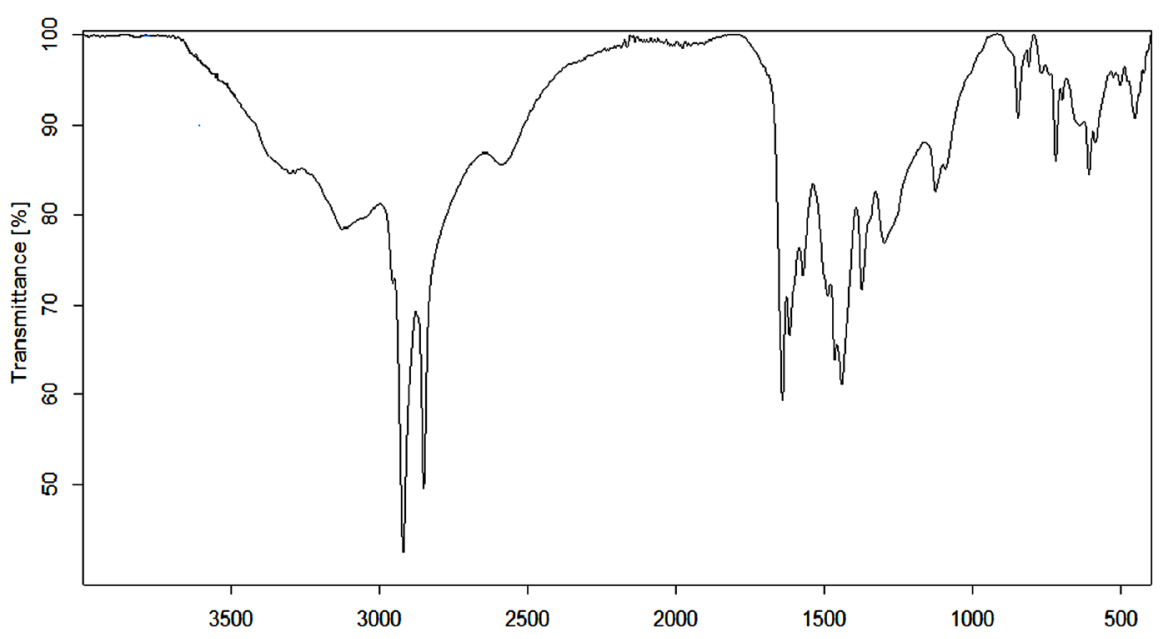

Figure 3. IR-spectrum for a mixture of amino-pentadecylphenols. 
The ${ }^{1} \mathrm{H}-\mathrm{NMR}\left(500 \mathrm{MHz}, \mathrm{CDCl}_{3}\right.$ ) (Figure 4) $\delta 0.9$ $3.0 \mathrm{ppm}=$ aliphatic protons in the same manner as for compounds (2) and (3). In addition, a singlet proton peak at $\delta 7.2$ associated with mixed chemical exchangeable protons of the aromatic amine - $\mathrm{NH}$ and phenolic - $\mathrm{OH}$.

\subsection{Co-Polymerization of APP and EGDMA}

A mixture of APP components was used for polymerization without an attempts separation. Polymerization of APP and EGDMA was done through aza-Michael addition starting with $1.05 \mathrm{~g}$ of APP and $5 \mathrm{~mL}$ of EGDMA. Without initiator, polymerization reaction was performed by setting the vessel to the refluxing mantle. The refluxing was done at a temperature of $180^{\circ} \mathrm{C}$ for eight hours. The product was filtered and the residues washed with excess ethanol followed by dichloromethane. $1.65 \mathrm{~g}$ of polymer was obtained. The polymer particles were characterized by FT-IR and Scanning Electron Microscopy (SEM).

\subsection{Characterization of the Co-Polymer Particles}

Scanning electron microscopy (SEM) was used to study the surface morphologies and grain size of the co-polymer materials. Perkin-Elmer 2000 FTIR spectrophoto- meter was employed in the determination of the surface functional groups of the co-polymer particles. The spectra were recorded from 4000 to $600 \mathrm{~cm}^{-1}$. Furthermore, the amount of amino functional groups incorporated onto the co-polymer surfaces were determined by an acid titration method. The amount of surface bound species is equivalent to the amount of $\mathrm{HCl}$ acid consumed.

\subsection{Cr(III) Adsorption Experiments}

Chromium (III) adsorption isotherms were obtained using a batch equilibration procedure. Duplicate $0.015 \mathrm{~g}$ polymer particles were equilibrated for $4 \mathrm{~h}$ with $100 \mathrm{ml}$ of aqueous solutions of $\mathrm{Cr}(\mathrm{III})$ with concentrations ranging from 0.16 to $20.00 \mathrm{mg} / \mathrm{L}$. The $\mathrm{pH}$ values of the test solutions were maintained at $\mathrm{pH} 6.0$ by adding $\mathrm{HCl}$ or $\mathrm{NaOH}$ solutions, a pH that was well below the precipitation level of chromium $(\mathrm{pH}>8)$ [17]. After equilibration the content of each flask were filtered through a Whatman No. 50 filter paper, and the filtrate analyzed for $\mathrm{Cr}(\mathrm{III})$ ion using atomic absorption spectrophotometer (novAA 400, Analytic Jena AG). The Cr(III) ions were removed from the adsorbents by washing with dilute $\mathrm{HCl}$ followed by distilled water. After filtration and drying, the recovered adsorbents were reused in a fresh batch as explained earlier.

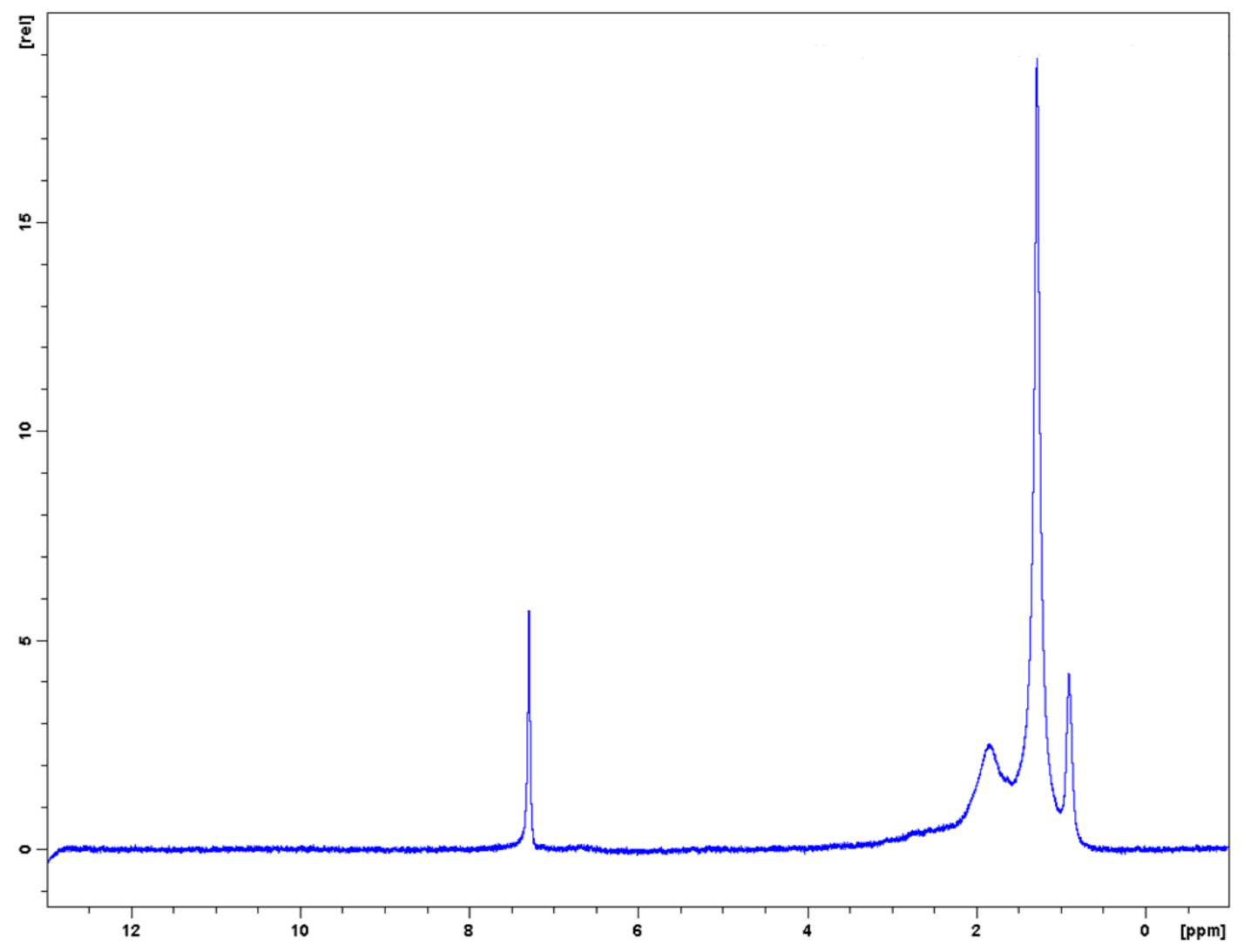

Figure 4. ${ }^{1} \mathrm{H}$-NMR (500 $\mathrm{MHz}, \mathrm{CDCl}_{3}$ ) spectrum for a mixture of amino-pentadecylphenols. 


\section{Results and Discussion}

\subsection{Synthesis and Characterization of Poly(APP-co-EGDMA) Particles}

Figure 5 shows FTIR spectrum of the poly(APP-coEGDMA) particles. For the synthesized polymer, important peaks include those at around $1125-1572 \mathrm{~cm}^{-1}$ which signify the presence of amines, as well as a broad band around $3100 \mathrm{~cm}^{-1}$, which is attributed to phenolic characteristics.

As determined by acid titration method, the loading of -NH groups on the surface of the synthesized poly(APPco-EGDMA) particles was found to be $46 \mathrm{mmol}$ per $\mathrm{g}$ of dry polymer. This amount is higher than most amino groups loadings found in functionalized mesoporous silicas. For instance, the Santa Barbara Amorphous material (SBA-15) containing one, two and three amino functional groups have amine loading ranging from 0.9 to 6.0 $\mathrm{mmol} / \mathrm{g}$ [18]. The reason for this abnormally high loading can be attributed to the flexibility of the co-polymer, which renders the accessibility of the amine groups to neutralization reaction.

Figure 6 shows the morphology of the prepared polymer particles. It is apparent from this figure that the poly(APP-co-EGDMA) particles obtained were spherical and of small size. Although these particles were found to have sizes ranging from $0.5-2.5 \mu \mathrm{m}$, about $50 \%$ of the particles had sizes in the range $1-1.5 \mu \mathrm{m}$, thus signifying a narrow size distribution (Figure 7).

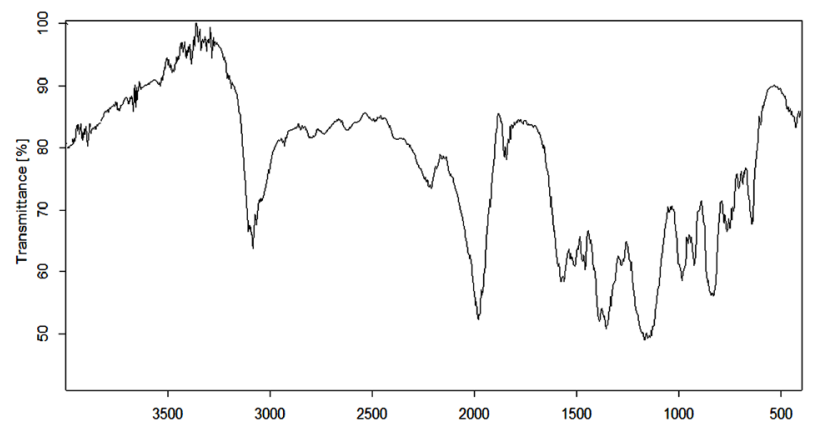

Figure 5. FTIR spectrum of the poly(APP-co-EGDMA) particles.

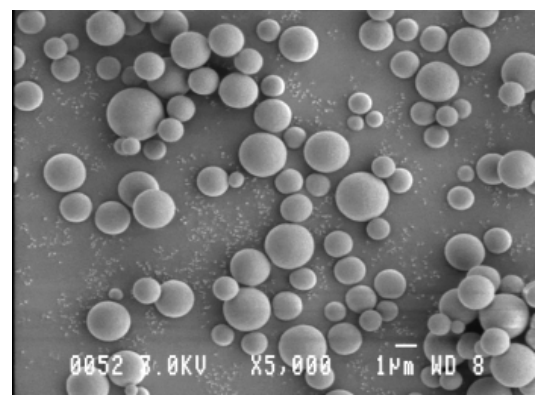

Figure 6. A SEM micrograph of poly(APP-co-EGDM) particles.

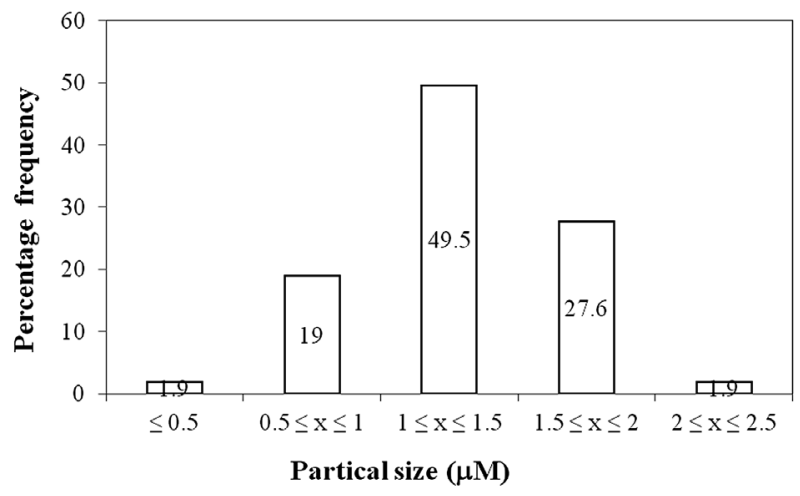

Figure 7. A histogram showing particle size distribution of the poly(APP-co-EGDM) particles.

\subsection{Adsorption Isotherm Studies}

$\mathrm{Cr}(\mathrm{III})$ ions adsorption on the synthesized poly(APP-coEGDM) particles at different ion concentrations was investigated. The adsorption test was done by batch method as explained elsewhere [19]. Results for the Cr(III) adsorption are shown in Figure 8, with removal efficiencies calculated using Equation (1).

$$
\text { Removal efficiency }(\%)=\left(C_{i}-C / C_{i}\right) \times 100 \%
$$

where, $C_{\mathrm{i}}$ and $C$ represent the initial and equilibrium concentrations (mg/L), respectively. As seen from this figure, the percentage $\mathrm{Cr}(\mathrm{III})$ ion adsorption decreased from $75 \%$ to $11 \%$ with the increase in initial concentrations of $\mathrm{Cr}(\mathrm{III})$ ions from 0.16 to $20.00 \mathrm{mg} / \mathrm{L}$. This is the indication that the $\mathrm{Cr}(\mathrm{III})$ ions uptake is predominantly dependent on initial $\mathrm{Cr}(\mathrm{III})$ ion concentration. At low concentrations, $\mathrm{Cr}(\mathrm{III})$ ions are adsorbed at specific sites, but with increasing $\operatorname{Cr}(\mathrm{III})$ ion concentrations the sites tend to be saturated very fast.

Generally at the lower $\mathrm{Cr}(\mathrm{III})$ ion concentrations, the removal percentage was higher due to a larger surface area of the polymer being available for the adsorption of $\mathrm{Cr}$ (III) ions. When the concentration of the $\mathrm{Cr}$ (III) ions became higher, the removal percentage was lower because the available sites for the adsorption became less. At a higher initial $\mathrm{Cr}(\mathrm{III})$ ion concentration, the ratio of initial number of moles of $\mathrm{Cr}$ (III) ion to the available adsorption surface area was high and as a result adsorption percentage was less.

To examine the relationship in distribution between adsorbed $\left(C_{a d s}\right)$ and equilibrium $\mathrm{Cr}(\mathrm{III})$ ion concentration $\left(C_{e q}\right)$, adsorption isotherm models are widely employed for fitting the data. The most widely used isotherm models are the Langmuir and Freundlich equations. Whereas the Langmuir model assumes that the uptake of metal ions occurs on a homogenous surface by monolayer adsorption without any interaction between adsorbed ions, the Freundlich model is more empirical and it assumes a heterogeneous adsorption due to the diversity of the ad- 


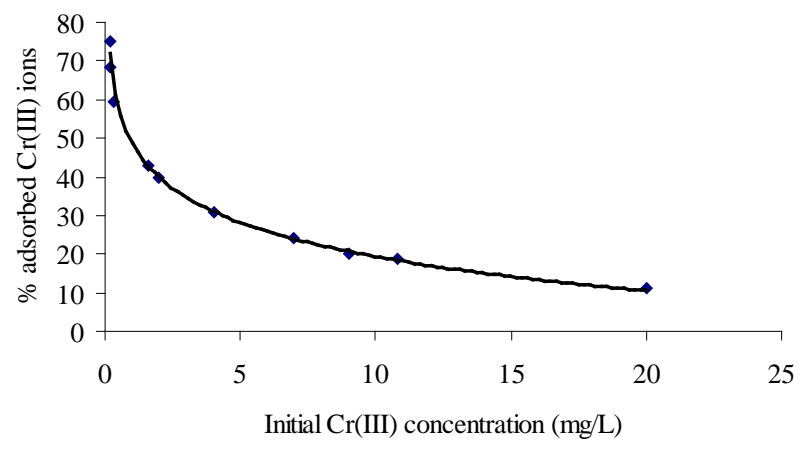

Figure 8. A plot of initial concentration of $\mathrm{Cr}^{+3}$ ion as a function of percentage $\mathrm{Cr}^{+3}$ ion adsorbed by $0.15 \mathrm{~g}$ of poly(APP-co-EGDMA) particles per litre of solution containing varying $\mathrm{Cr}^{+3}$ ion concentration.

sorption sites or the diverse nature of the metal ions adsorbed, free or hydrolyzed species. To get the equilibrium data, initial $\mathrm{Cr}$ (III) ions concentration were varied while the adsorbent mass in each sample was kept constant. A graph of $\mathrm{Cr}(\mathrm{III})$ ions adsorbed on poly(APP-coEGDMA) particles, $C_{a d s}(\mathrm{mg} / \mathrm{g})$, was then plotted as a function of the equilibrium solute concentration $C_{e q}(\mathrm{mg} / \mathrm{L})$ (Figure 9). As seen from the figure, initially the isotherm curve is characterized by a region which is concave to the concentration axis, and then it reaches a plateau where there is no more adsorption. The obtained data were correlated with a linearised form of the Langmuir Equation (2),

$$
\frac{C_{e q}}{C_{a d s}}=\left(\frac{1}{K_{a} q_{m}}\right)+\frac{C_{e q}}{q_{m}}
$$

where, $q_{m}$ is the maximum adsorption capacity $(\mathrm{mg} / \mathrm{g})$ and $K_{a}$ is the equilibrium constant related to the energy of adsorption (L/mg).

A typical plot is given in Figure 10. As seen from the figure, the data seem to be well described by the linear form of the Langmuir equation with $\mathrm{R}^{2}$ value of 0.99 . The high degree of the correlation coefficient $\left(\mathrm{R}^{2}\right)$ for the linearized Langmuir relationship suggests that a single surface reaction with constant activation energy is the predominant sorption step [7]. This is also in line with the gradual decrease in the percentage of $\operatorname{Cr}(\mathrm{III})$ ions removed from the solution as the initial concentration was increased (Figure 8). The values of the Langmuir adsorption parameters i.e. $q_{m}$ and $K_{a}$ deduced from the slopes and intercepts of the plot are $16 \mathrm{mg} / \mathrm{g}$ and 0.6 $\mathrm{L} / \mathrm{mg}$, respectively.

The Freundlich adsorption model was also applied to the adsorption of the $\mathrm{Cr}$ (III) ions. A typical plot from the linearised Freundlich Equation (3) is given in Figure 11.

$$
\log C_{\text {ads }}=\log k+\left(\frac{1}{\mathrm{n}}\right) \log C_{\text {eq }}
$$

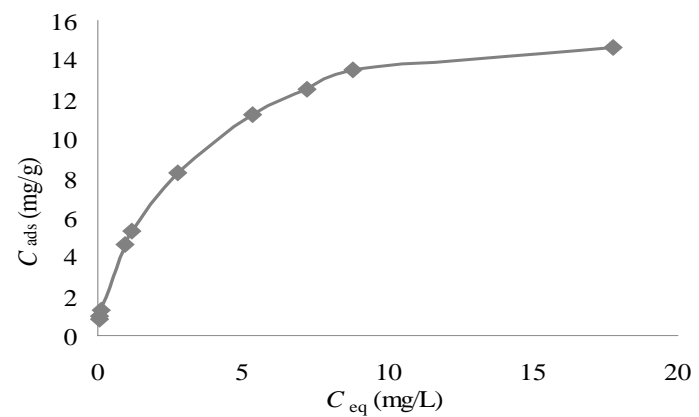

Figure 9. $\mathrm{Cr}$ (III) ions adsorption isotherm on poly(APPco-EGDMA) particles.

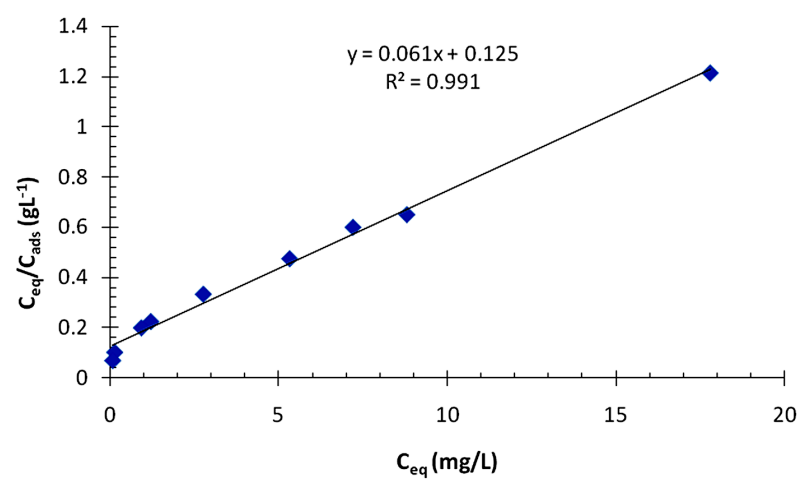

Figure 10. A Langmuir plot for the adsorption of $\mathbf{C r}$ (III) ions on poly(APP-co-EGDMA) particles.

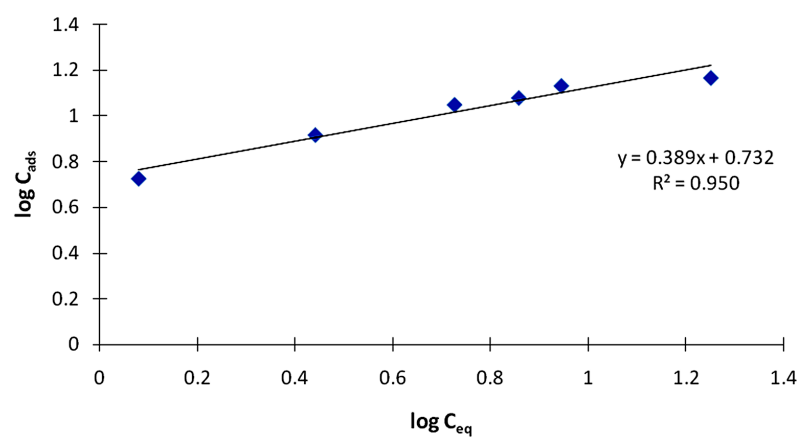

Figure 11. A Freundlich plot for the adsorption of $\mathrm{Cr}$ (III) ions on poly(TAPP-co-EGDMA) particles.

Results indicated that the value of $\mathrm{R}^{2}$ is about 0.95 . The relatively low correlation of the Freundlich equation over the Langmuir equation proves further that the adsorption process is mainly monolayer. The coefficient $k$ is a parameter that reflects the amount of the active adsorption site and $\mathrm{n}$ characteristic coefficient related to energy or intensity of adsorption. Values of $\mathrm{n}$ between 2 and 10 indicate a good adsorption [24]. The values of $n$ and $k$ obtained from this study were 2.6 and 5.4, respectively.

\subsection{Polymer Reusability}

After washing the polymer with dilute acid followed by 
distilled water, the polymer particles were dried at $50^{\circ} \mathrm{C}$ and then allowed to cool to room temperature. The materials were then used in a fresh adsorption experiment. Results indicated that the reused materials have an adsorption maxima of $13 \mathrm{mg} \mathrm{Cr}(\mathrm{III})$ per $\mathrm{g}$, which is over $80 \%$ efficiency as compared to the freshly prepared poly(APPco-EGDMA) particles.

\subsection{Comparison of $\operatorname{Cr}$ (III) Removal with Different Adsorbents Reported in the Literature}

The adsorption capacity of the poly(APP-co-EGDMA) adsorbent for the removal of Cr(III) was compared with other adsorbents reported in the literature, and the values of the adsorption capacities are presented in Table 1. As it can be seen from the table, the sorption capacity of poly(APP-co-EGDMA) is comparable with the reported ones. The variations in adsorption capacity that are observed could be attributed to the characteristics of the individual adsorbent, the extent of surface/surface modification, the $\mathrm{pH}$, and the initial concentration of the adsorbate [25].

\section{Conclusion}

Poly(APP-co-EGDMA) particles were successfully synthesized by a copolymerization of a mixture of amino pentadecylphenols (derived from CNSL) and ethylene glycol dimethacrylate. Characterization of the poly(APPco-EGDMA) particles indicated that they are spherical in nature, with grain size ranging from $0.5-2.5 \mu \mathrm{m}$. The particles had an amino group loading of $46 \mathrm{mmol} / \mathrm{g}$. The prepared co-polymer particles were found to have a maximum adsorption capacity for Cr(III) ions of $16 \mathrm{mg}$ per $\mathrm{g}$ of dry polymer. The spent polymer particles were recoverable and reusable.

Table 1. A comparison of $\mathbf{C r}$ (III) removal with different adsorbents reported in the literature.

\begin{tabular}{cccc}
\hline $\begin{array}{c}\text { Sample } \\
\text { No. }\end{array}$ & Adsorbent & $\begin{array}{c}\text { Adsorption } \\
\text { capacity (mg/g) }\end{array}$ & Reference \\
\hline 1 & Poly(APP-co-EGDMA) & 16 & This study \\
2 & $\begin{array}{c}\text { Activated carbon from } \\
\text { cashew nut shells }\end{array}$ & 13.93 & {$[5]$} \\
3 & $\begin{array}{c}\text { Poly-5-allyl-calix [4] arene } \\
\text { tetra carboxylic acid }\end{array}$ & 11.89 & {$[20]$} \\
4 & Wood pulp & 4.7 & {$[21]$} \\
5 & Sorghum straw & 6.96 & {$[22]$} \\
6 & Rubber wood fibre & 18.24 & {$[23]$} \\
\hline
\end{tabular}

\section{Acknowledgements}

The authors would like to thank the University of Dar es Salaam and St. John's University of Tanzania for logistical and financial support.

\section{REFERENCES}

[1] P. C. Nagajyoti, K. D. Lee and T. V. M. Sreekanth, "Heavy Metals, Occurrence and Toxicity for Plants: A Review," Environmental Chemistry Letters, Vol. 8, No. 3, 2012, pp. 199-216. http://dx.doi.org/10.1007/s10311-010-0297-8

[2] N. A. N. Nik Malek and A. Mohd Yusof, "Removal of Cr(III) from Aqueous Solutions Using Zeolite Clay Prepared from Rice Husks Ash,” The Malaysian Journal of Analytical Sciences, Vol. 11, No. 1, 2007, pp. 76-83.

[3] K. Lock and C. R. Janssen, "Ecotoxicity of Chromium (III) to Eisenia Fetida, Enchytraeus Albidus, and Folsomia Candida," Ecotoxicology and Environmental Safety, Vol. 51, No. 3, 2002, pp. 203-205. http://dx.doi.org/10.1006/eesa.2001.2122

[4] T. S. Anirudhan and R. G. Radhakrishnan, "Chromium (III) Removal from Water and Wastewater Using Carboxylate-Functionalised Cation Exchange Prepared from a Lignocellulosic Residue," Journal of Colloid and Interface Science, Vol. 316, No. 2, 2007, pp. 268-276. http://dx.doi.org/10.1016/j.jcis.2007.08.051

[5] S. Tangjuank, N. Insuk, V. Udeye and J. Tontrakoon, "Chromium(III) Sorption from Aqueous Solutions Using Activated Carbon Prepared from Cashew Nut Shells," International Journal of Physical Science, Vol. 4, No. 8, 2009, pp. 412-417.

[6] M. Sen and M. Ghosh Dastidar, "Chromium Removal Using Various Biosorbents,” Iran Journal of Environmental and Health Science Engineering, Vol. 7, No. 3, 2010, pp. 182-190.

[7] M. M. Nasef, H. Saidi, Z. Ujang and K. Z. M. Dahlan, "Removal of Metal Ions from Aqueous Solutions Using Crosslinked Polyethylene-GTMFJ-Polystyrene Sulfonic Acid Adsorbent Prepared by Radiation Grafting," Journal of the Chilean Chemical Society, Vol. 55, No. 4, 2010, pp. 421427. http://dx.doi.org/10.4067/S0717-97072010000400002

[8] H. Eisazadeh, "Removal of Chromium from Waste Water Using Polyaniline,” Journal of Applied Polymer Science, Vol. 104, No. 3, 2007, pp. 1964-1967. http://dx.doi.org/10.1002/app.25904

[9] R. Ansari, “Application of Polyaniline and Its Composites for Adsorption/Recovery of Chromium (VI) from Aqueous Solutions," Acta Chimica Slovenica, Vol. 53, 2006, pp. 88-94.

[10] H. Eisazadeh, "Removal of Arsenic in Water Using Polypyrrole and Its Composites," Applied Science Journal, Vol. 3, No. 1, 2008, pp. 10-13.

[11] S. Y. Prabawati, Jumina, S. J. Santosa and Mustofa, "Synthesis of Polypropylcalix [6] Arene from P-t-butylphenol as Adsorbent for Cr(III) Metal Ion,” Indonesian Journal of Chemistry, Vol. 11, No. 1, 2011, pp. 37-42. 
[12] B. C. Pan, W. M. Zhang, B. J. Pan, H. Qiu, Q. R. Zhang, Q. X. Zhang and S. R. Zheng, "Efficient Removal of Aromatic Sulfonates from Wastewater by a Recyclable Polymer: 2-Naphthalene Sulfonate as a Representative Pollutant," Environmental Science \& Technology, Vol. 42, 2008, pp. 7411-7416. http://dx.doi.org/10.1021/es801370n

[13] A. Denizli, N. Sanli, B. Garipcan, S. Patir and G. Alsancak, "Methacryloylamidoglutamic Acid Incorporated Porous Poly-(methylmethacrylate) Beads for Heavy-Metal Removal," Industrial Engineering Chemistry Research, Vol. 43, 2004, pp. 6095-6101. http://dx.doi.org/10.1021/ie030204z

[14] A. Nastasovic, S. Jovanovic, D. Dordevic, A. Onjia, D. Jakovljevic and T. Novakovic, "Metal Sorption on Macroporous Poly(GMA-co-EGDMA) Modified with Ethylene Diamine," Reactive and Functional Polymers, Vol. 58, No. 2, 2004, pp. 139-147. http://dx.doi.org/10.1016/j.reactfunctpolym.2003.11.015

[15] R. Kunin, "The Use of Macroreticular Polymeric Adsorbents for the Treatment of Waste Effluents," Pure and Applied Chemistry, Vol. 46, No. 2-4, 1976, pp. 205-211. http://dx.doi.org/10.1351/pac197646020205

[16] R. Paramashivappa, P. Zolfigol, P. Kumar, P. J. Vithayathil and A. S. Rao, "Novel Method for Isolation of Major Phenolic Constituents from Cashew (Anacardium Occidentale L.) Nut Shell Liquid,” Journal of Agricultural and Food Chemistry, Vol. 49, No. 5, 2001, pp. 2548-2551. http://dx.doi.org/10.1021/jf001222j

[17] A. Esmaeili, A. Mesdaghi nia and R. Vazirinejad, "Chromium (III) Removal and Recovery from Tannery Wastewater by Precipitation Process," American Journal of Applied Sciences, Vol. 2, No. 10, 2005, pp. 1471-1473. http://dx.doi.org/10.3844/ajassp.2005.1471.1473

[18] J. Aguado, J. M. Arsuaga, A. Arencibia, M. Lindo and V. Gascón, “Aqueous Heavy Metals Removal by Adsorption on Amine-Functionalized Mesoporous Silica," Journal of Hazardous Materials, Vol. 163, No. 1, 2009, pp. 213-221. http://dx.doi.org/10.1016/j.jhazmat.2008.06.080

[19] L. L. Mkayula, M. M. Y. Makame and T. H. Mtechi, "Preparations of Spherical Polymeric Particles from Tanzania Cashew Nut Shell Liquid by Suspension Polymerization," Tanzania Journal of Science, Vol. 30, No. 2, 2004, pp. 1-10.

[20] S. H. J. Desi, S. M. Dwi, O. Keisuke and K. Hidetaka "Adsorption of $\mathrm{Pb}(\mathrm{II}), \mathrm{Cd}(\mathrm{II})$, and $\mathrm{Cr}(\mathrm{III})$ from Aqueous Solution by Poly-5-allyl-calix[4]arene Tetra Carboxylic Acid,” Indian Journal of Chemistry, Vol. 11, No. 2, 2011, pp. 191-195.

[21] A. M. A. Nada, M. Y. Alkady and H. M. Fekry, "Synthesis and Characterization of Grafted Cellulose for Use in Water and Metal Ions Sorption,” BioResources, Vol. 3, No. 1, 2007, pp. 46-59.

[22] G. R. Bernado, R. M. Rene and A. D. Ma. Catalina, "Chromium (III) Uptake by Agro-Waste Biosorbents: Chemical Characterization, Sorption-Desorption Studies,” Journal of Hazardous Materials, Vol. 170, No. 2-3, 2009, pp. 845-854.

[23] M. Mahdavi, M. B. Ahmadi, M. J. Haron and M. Z. Ad. Ramadhani, "Adsorption of Cr(III) from Aqueous Solution by Polycrylamide-Crafted Rubber Wood Fibre. Kinetics, Equilibrium and Thermodynamic Studies," BioResource, Vol. 6, No. 1, 2011, pp. 22-33.

[24] E. Erdem, N. Karapinar and R. Donat, "The Removal of Heavy Metal Cations by Natural Zeolites,” Journal of Colloid and Interface Science, Vol. 280, No. 2, 2004. pp 309314. http://dx.doi.org/10.1016/j.jcis.2004.08.028

[25] M. R. Gandhi, N. Viswanathan and S. Meenakshi, "Synthesis and Characterization of a Few Amino-Functionalized Copolymeric Resins and Their Environmental Applications," Industrial \& Engineering Chemistry Research, Vol. 51, No. 16, 2012, pp. 5677-5684. http://dx.doi.org/10.1021/ie3000503 